\title{
False memory susceptibility in coma survivors with and without a near-death experience
}

\section{Charlotte Martial, Vanessa Charland- Verville, Hedwige Dehon \& Steven Laureys}

\section{Psychological Research}

An International Journal of Perception, Attention, Memory, and Action

ISSN 0340-0727

Psychological Research DOI 10.1007/s00426-017-0855-9

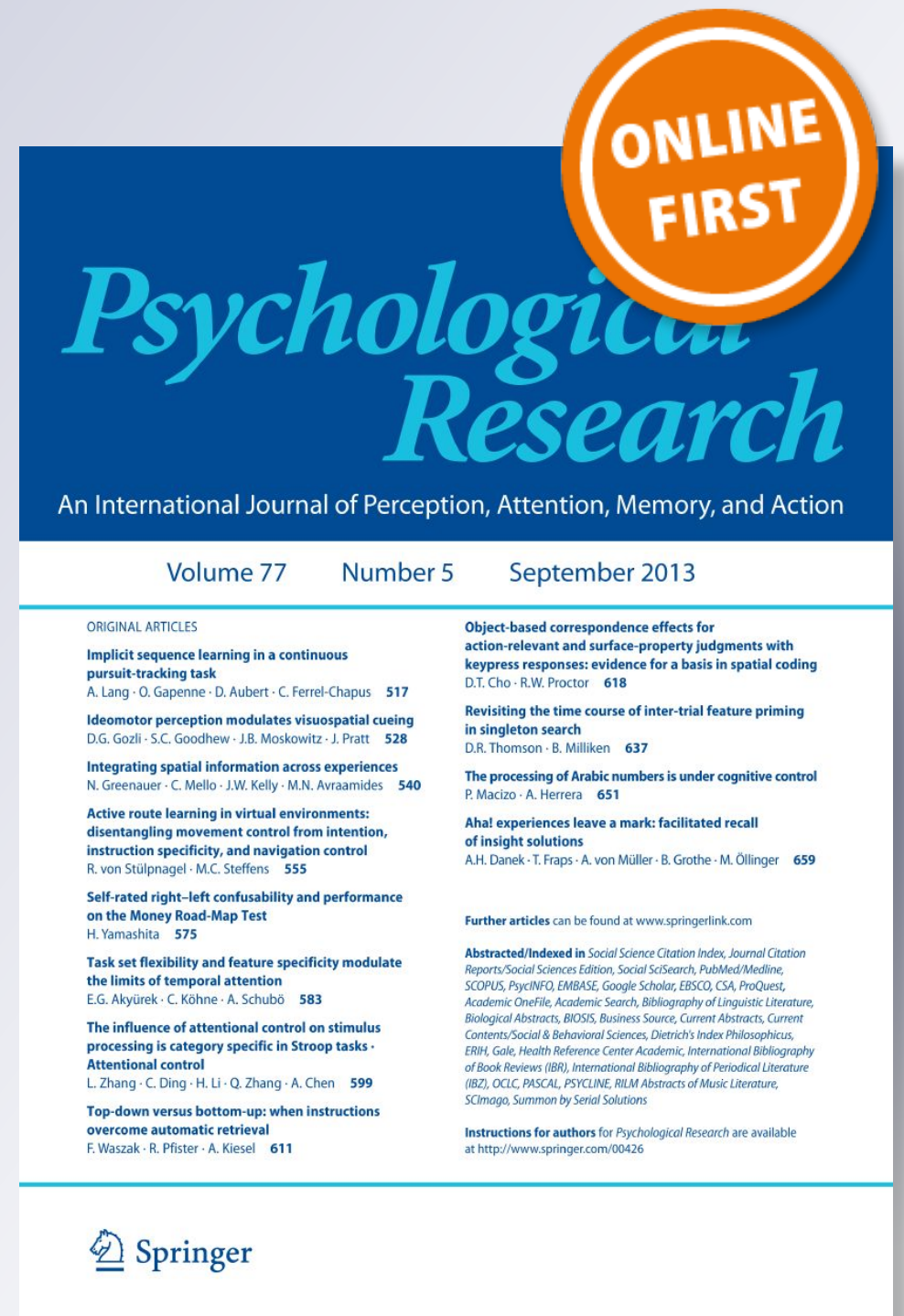

Springer 
Your article is protected by copyright and all rights are held exclusively by SpringerVerlag Berlin Heidelberg. This e-offprint is for personal use only and shall not be selfarchived in electronic repositories. If you wish to self-archive your article, please use the accepted manuscript version for posting on your own website. You may further deposit the accepted manuscript version in any repository, provided it is only made publicly available 12 months after official publication or later and provided acknowledgement is given to the original source of publication and a link is inserted to the published article on Springer's website. The link must be accompanied by the following text: "The final publication is available at link.springer.com". 


\title{
False memory susceptibility in coma survivors with and without a near-death experience
}

\author{
Charlotte Martial $^{1}{ }^{1} \cdot$ Vanessa Charland-Verville $^{1} \cdot$ Hedwige Dehon $^{2} \cdot$ \\ Steven Laureys ${ }^{1}$
}

Received: 24 August 2016 / Accepted: 2 March 2017

(C) Springer-Verlag Berlin Heidelberg 2017

\begin{abstract}
It has been postulated that memories of neardeath experiences (NDEs) could be (at least in part) reconstructions based on experiencers' (NDErs) previous knowledge and could be built as a result of the individual's attempt to interpret the confusing experience. From the point of view of the experiencer, NDE memories are perceived as being unrivalled memories due to its associated rich phenomenology. However, the scientific literature devoted to the cognitive functioning of NDErs in general, and their memory performance in particular, is rather limited. This study examined NDErs' susceptibility to false memories using the Deese-Roediger-McDermott (DRM) paradigm. We included 20 NDErs who reported having had their experience in the context of a life-threatening event (Greyson NDE scale total score $\geq 7 / 32$ ) and 20 volunteers (matched for age, gender, education level, and time since brain insult) who reported a life-threatening event but without a NDE. Both groups were presented with DRM lists for a recall task during which they were asked to assign "Remember/Know/Guess" judgements to any recalled response. In addition, they were later asked to complete a post-recall test designed to obtain estimates of activation and monitoring of critical lures. Results demonstrated that NDErs and volunteers were equally likely to produce
\end{abstract}

H. Dehon and S. Laureys contributed equally to this work.

Charlotte Martial

coma@chu.ulg.ac.be; cmartial@ulg.ac.be

1 Coma Science Group, GIGA Research Center and Neurology Department, University and University Hospital of Liège, Avenue de l'Hôpital, 11, 4000 Liège, Belgium

2 Cognitive and Behavioral Clinical Psychology Unit, Psychology and Neuroscience of Cognition Research Unit (PsyNCog), University of Liège, Liège, Belgium false memories, but that NDErs recalled them more frequently associated with compelling illusory recollection. Of particular interest, analyses of activation and monitoring estimates suggest that NDErs and volunteers groups were equally likely to think of critical lures, but source monitoring was less successful in NDErs compared to volunteers.

\section{Introduction}

"Near-Death Experiences" (NDEs) are physiological and neurological phenomena that have provoked curiosity all around the world and generated several myths and legends. To date, there is still no consensus regarding to the definition of NDEs in the scientific community, but the phenomenon has been previously described as "profound psychological events with transcendental and mystical elements typically occurring to individuals close to death or in situations of intense physical or emotional danger" (Greyson, 2000a). These experiences are usually recalled after lifethreatening events, such as cardiac arrest (Greyson, 2003; Parnia, Waller, Yeates, \& Fenwick, 2001; van Lommel, van Wees, Meyers, \& Elfferich, 2001) or traumatic brain injury (Hou, Huang, Prakash, \& Chaudhury, 2013), but also after non-life-threatening events (Charland-Verville et al., 2014), such as syncope (Lempert, Bauer, \& Schmidt, 1994) or a meditative state (Beauregard, Courtemanche, \& Paquette, 2009). Although the definition and causes of NDEs are still a matter of debate, these experiences appear to occur during an altered state of consciousness (Greyson \& Stevenson, 1980; Ring, 1980) and seem to contain recurrent components (e.g., feeling of peacefulness, out-of-body experiences (OBEs); Blanke \& Dieguez, 2009; CharlandVerville et al., 2014; Facco \& Agrillo, 2012). Furthermore, although some theories could contribute to the explanation 
of specific NDE components-such as OBEs, seeing a bright light, life review, and so on-none of these can single-handedly explain the entire experience and its associated rich phenomenology.

Blackmore (1993) postulated that NDEs could be explained by both physiological and psychological mechanisms. According to her theory, the core NDE is biologically determined, but the interpretation and details of the NDE can be influenced by the experiencer's top-down cognitive processes. These include previous and/or general knowledge, beliefs, and expectations about the world. The emergence of NDE components in memory could, therefore, be related to these processes, leading to a modification of the model of reality experienced by the individuals (Blackmore, 1993). The resulting memory of this experience could thus be, in part, internally generated or imagined (see also French, 2001). In parallel, it is now well established that top-down processes (in the form of cognitive schema representing activated knowledge stored in memory; e.g., a mental representation of knowledge) actively elaborate the information, usually to comprehend it. These mechanisms have been shown to be particularly active in situations of physical or psychological threat and when the perceptive features are ambiguous-similar contexts classically associated with the emergence of a NDEto resolve this ambiguity. Therefore, we may postulate that NDEs could be built as a result of the individuals' attempt to interpret their highly stressful and confusing experiences (Braithwaite, 2008) to preserve a coherent interpretation of the events associated with episodes of altered consciousness. In support of this reconstructive view, the NDErs' religiosity and cultural background have been suggested to influence the NDEs' content and the features' interpretation (Belanti, Perera, \& Jagadheesan, 2008; Greyson, 2007). Other studies (Ellwood, 2000; Kellehear, 1993; Kellehear \& Irwin, 1990; Pasricha \& Stevenson, 1986) have also noted that certain features of NDE seem to be culturebound phenomena and this supports rather non-physiological theories assuming the influence of knowledge, beliefs, and expectations of NDErs. Nevertheless, very few articles have examined the particularity of NDE memories (see Greyson, 2007; van Lommel, 2011). Recently, Thonnard et al. (2013) examined the phenomenological characteristics of NDEs and compared them with imagined memories using the Memory Characteristics Questionnaire (MCQ; Johnson, Foley, Suengas, \& Raye, 1988), a questionnaire designed to assess phenomenological characteristics of real and imagined memories. They showed that NDE memories contained more phenomenological characteristics (e.g., emotions, and contextual and sensory information) than real event memories or coma memories which did not classify as a NDE based on the Greyson NDE scale (i.e., total score of Greyson $\leq 7$; Greyson, 1983). This suggests that NDEs memories cannot be considered as imagined but rather as a sort of "hyper reality". Shortly thereafter, Palmieri et al. (2014) investigated neural activity-using electroencephalography (EEG) - associated with the recall of NDE memories and suggested that, at a neural level, NDE memories are stored as "episodic memories of events experienced in a peculiar state of consciousness" (p. 13) and not as an imagined events memories. The authors then suggested that NDE memories might likely be "hallucination-like memories of actually perceived hallucinations" (p. 13). As suggested by Agrillo (2011), this raises the crucial question as to where and how the brain can store this experience. At present, no current theory can account for the rich phenomenology associated with NDE memories, distinguishing them from imagined events (Palmieri et al., 2014; Thonnard et al., 2013), while we cannot be certain that this experience was lived in reality.

In parallel, some authors have proposed that reports of NDE could be altered memories of real events and could be comparable to false memories (Braithwaite, 2008; French, 2001). Nonetheless, to our knowledge, no study has directly examined this hypothesis, that is, whether or not NDErs are particularly prone to false memory production. In laboratory settings, such memory distortions can be reliably elicited with the Deese-Roediger-McDermott (DRM; Deese, 1959; Roediger \& McDermott, 1995) paradigm, the most largely used tool to study the production of false memories (see Gallo, 2006, 2010 for reviews). In this procedure, individuals are presented with lists of semantically associated words (e.g., thread, pin, eye,...) that converge on an unstudied semantic associate (e.g., needle), an item called "critical lure" (i.e., the false memory). Later, when asked to remember the word lists, participants are highly susceptible to falsely recall or recognize this critical lure as being a word included in the presented list. The DRM illusion is robust to a variety of manipulations (e.g., persistence across a variety of encoding tasks, retention intervals, and test formats) and has been observed in a variety of populations (e.g., younger and older participants, patients with neurological impairments, and participants of different languages and cultures). More relevant for the current study, DRM illusions are typically accompanied by a compelling subjective experience. That is, participants are quite confident that the critical lure has been presented, and are able to recollect details related to its supposed presentationa phenomenon called "illusory" (e.g., Gallo \& Roediger, 2003) or "phantom" (e.g., Brainerd, Wright, Reyna, \& Mojardin, 2001) recollection (see Dehon, 2012 for a recent review). Dehon (2012) defined this phenomenon as "the subjective detailed feeling of remembering that sometimes accompanies false remembering of events that never happened" (p. 51). In the DRM paradigm, this can be measured with the "Remember/Know" procedure (Tulving, 
1985). This procedure involves asking participants to differentiate between words that they actually recall with any specific detail related to his presentation and those based on a strong feeling of familiarity. It is then possible to consider a DRM false memory as a falsely recalled critical lure associated with illusory recollection (i.e., accompanied by "Remember" judgements; see Dehon, 2012; Gallo, McDermott, Percer, \& Roediger, 2001; Gallo \& Roediger, 2003), and not as recalled lures purely based on a strong feeling of familiarity. According to the activation-monitoring theory (e.g., McDermott \& Watson, 2001; Roediger, Balota, \& Watson, 2001), false memories result from a two-stage theoretical process: when we hear a list of words, we think about the critical lure (i.e., an internally derived word) which was not presented, thus making it more easily accessible through spreading activation in the semantic network. The heightened activation of the critical lure can then lead to disruption in the participant's source monitoring (Johnson, Hashtroudi, Lindsay, 1993) and this word is finally reported by the participant if he was not able to correctly attribute it to its actual source. Whereas an activation process enhances false memory, monitoring reduces it. Nuances of these two processes and their exact nature are still being investigated, but they seem cognitively distinct (Cabeza, Rao, Wagner, 2001; Roediger et al., 2001; Roediger \& Mcdermott, 2000).

The existing literature about false memory susceptibility has revealed that certain cognitive and personality characteristics may be involved in the occurrence of committing errors in memory. For example, Clancy and colleagues (2002) have shown using the DRM paradigm that people who report recovered memories of traumatic events that are unlikely to have occurred (in the case of this study: alien abduction) seem to be particularly prone to memory distortion. Moreover, the previous studies have demonstrated that susceptibility to false memories might be associated with a personal tendency to dissociation (Heaps \& Nash, 1999; Hyman \& Billings, 1999). Dissociation can be described as the detachment of thoughts, feelings, or experiences from the normal stream of consciousness and memory (Bernstein \& Putnam, 1986), and may reflect a failure to efficiently use monitoring processes or the use of lax criteria to interpret experiences (Johnson, 2006). Nonpathological dissociation can be considered as a normally distributed trait in the population and appears to be related to how people process and integrate experiences (Farina \& Liotti, 2013). More specifically, it has been demonstrated that dissociative tendencies are directly related to reality discrimination difficulties (e.g., Varese, Barkus, \& Bentall, 2012). Several studies have shown a positive correlation between the DRM illusion and the scores on the Dissociative Experiences Scale (DES; e.g. Hyman \& Billings, 1999; Winograd, Peluso, \& Glover, 1998), suggesting that a tendency towards dissociative experiences is associated with increased rates of false recall. Dehon et al. (2008) not only replicated this association between the DES and the DRM illusion, but also found (through the use of a modified DRM procedure; Brédart, 2000) that this relationship was mediated by the (source) monitoring component. In parallel, Greyson (2000b) also used the DES as a measure of dissociative symptoms but in near-death survivors. His study demonstrated that dissociative symptoms in NDErs were positively correlated with the depth of the NDE and could support the view that "NDEs involve a shifting of attention from the physical environment to an altered state of consciousness in which perception, cognitive functioning, emotional states, and sense of identity may be partly or completely disconnected from the mainstream of conscious awareness" (p. 463). This suggests that NDErs are more likely to have high-dissociative personality traits (Greyson, 2000b) and those specific traits, in return, seem to be linked to a higher tendency to reconstruct experiences (de Ruiter, Elzinga, Phaf, \& de Ruiter, 2006). Indeed, research has reported memory process changes in high-dissociative people (e.g., Veltman et al., 2005). We can then ask whether NDErs have certain cognitive characteristics, such as higher constructive capacities, that lead them to be more susceptible to creating false memories, since these capacities may induce failures such as memory distortions or errors.

To the best of our knowledge, very little is known about possible cognitive mechanisms associated with NDEs. In fact, no study has directly examined the influence of topdown memory processes in NDErs. One of the most effective ways to observe the implication of top-down cognitive influences, and memory reconstruction is to investigate false memory production, because it allows observing memory suggestibility and distortion (Loftus, 1996; Roediger \& McDermott, 1995). A cognitive explanation for NDE may be based on the fact that people experiencing them make erroneous use of their reality monitoring processes, and furthermore that NDEs might (at least in part) be considered as reconstructions based on experiencers' previous knowledge. This could be an explanation as to why NDE memories are then characterized by a sense of "phenomenological certainty" (Dell'Olio, 2010) from NDErs' perspective and perceived as "more real than real" (Thonnard et al., 2013). Thus, the aim of this study was to investigate the susceptibility of NDErs to report false memories and illusory recollection using the DRM paradigm, compared to matched volunteers. We then wanted to investigate activation and monitoring processes using Brédart's (2000) modified DRM paradigm procedure. After the free recall test, we added a post-recall test in which participants were asked to report items that they had thought of but did not recall. This design allows one to obtain estimates of activation and 
monitoring of critical non-presented lures during the task. Our first prediction was that NDErs and matched volunteers would be equally likely to accurately recall studied items presented in DRM lists, but that NDErs would be more likely to falsely recall critical lures compared to the volunteers. In addition, we expected to observe a higher rate of "Remember" judgements (i.e., more phenomenological information associated with produced false memories or illusory recollection) assigned to critical lures in NDErs compared to that of volunteers, while rates of "Remember" judgements assigned to studied items would be similar in both groups. Finally, we hypothesized that NDErs would produce a smaller proportion of non-presented critical lures during the post-recall test compared to volunteers, suggesting less efficient monitoring abilities.

\section{Materials and methods}

\section{Participants}

The experimental group consisted of 20 individuals who reported a NDE in the context of a life-threatening situation and that resulted in a coma of different etiologies: 9 anoxic, 3 traumatic brain injury, or 8 other (i.e., non-traumatic events such as an exacerbation of an on-going illness or complication during surgery). A control group matched for age, gender, education level, and time, since brain insult was also recruited. It was composed of 20 volunteers who reported having had similar life-threatening incidents (comparable etiologies leading to a period of coma: 9 anoxic, 3 traumatic brain injury, or 8 other etiology) but without a NDE. The presence of a NDE was identified using the Greyson NDE scale (i.e., total score $\geq 7$ ). The Greyson NDE scale is a validated (Greyson, 1983; Lange, Greyson, \& Houran, 2004) 16-item multiple-choice tool used to quantify the intensity of the NDE (i.e., total score ranging from 0 to 32) and to permit a standardized identification of NDEs with a total score cutoff of 7. The Greyson NDE scale assesses core content components of $16 \mathrm{NDE}$ features. For each item, the scores are arranged on an ordinal scale ranging from 0 to 2 (i.e., $0=$ "not present", $1=$ "mildly or ambiguously present", and $2=$ "definitively present"; Greyson, 1983; Lange et al., 2004).

NDErs and matched volunteers were recruited via the Website, publications, and appearances in local media of the Coma Science Group (University of Liège, Belgium). All participants were native French speakers and were screened by the experimenter for any signs of memory or cognitive impairment. None of the volunteers had a premorbid history of neurological or psychiatric disorders or previous history of alcohol or drug abuse. No incentive was offered for participation. Written informed consent was obtained from all the participants. The study was approved by the ethics committee of the Faculty of Medicine of the University of Liège.

\section{Materials}

\section{The DRM false memory task}

In the DRM procedure, participants were presented with lists of words (e.g., note, instrument, sound,...) converging on associated, non-presented lures (e.g. music), what is called a "critical lure". The material contains 12 French DRM word lists of 15 items each (materials from Dehon, 2006 and; Dehon et al., 2011). A female voice uttering the words was recorded and digitized. Lists were presented in random order using a computer. DRM list words were controlled for word length, associative strength, level of arousal, level of imagery, valence rating, and degree of identifiability.

Participants were also invited to detail the subjective experience, i.e., details related to the supposed presentation of the item (Lampinen, Neuschatz, \& Payne, 1998), called "illusory" recollection (e.g., Dehon, 2012). To do so, they were asked to distinguish memories that they actually recollect (conscious recollection) from those based on a strong feeling of familiarity (familiarity processes) using the "Remember/Know/Guess" judgements procedure (Tulving, 1985). These three types of judgements reflect qualitatively different forms of memory: a "Remember" judgement refers to a conscious recollection state (i.e., when they could consciously recollect details of the actual occurrence of the word), a "Know" judgement refers to the experience of familiarity in the absence of recollection (i.e., when they were confident that the item was presented in the list but could not remember anything about its presentation), and a "Guess" judgement is invoked in the case of there is no subjective experience and/or guessed responses based on its thematic similarity.

Furthermore, we used a modified DRM procedure (Brédart, 2000; Dehon, 2006; Dehon \& Bredart, 2004) in which a post-recall test was added after the free recall test. In this phase, participants were instructed to recall words that they had thought of but did not state in the recall phase, because those words were not uttered by the recorded voice. This modification of the procedure permits one to test whether the critical lure had been activated or not. Specifically, the additional phase required participants to precisely establish the source of memories and the recall of non-presented critical lures during this additional phase linked to a list that did not initially produce a false memory, thus allowing one to conclude that source monitoring succeeded. 


\section{The Mill Hill Vocabulary test}

The French version (Deltour, 1993) of the Mill Hill Vocabulary Scale (MHVS; Raven, Raven, \& Court, 1988) was also administered. The MHVS is a multiple-choice format test used to assess verbal ability.

\section{Procedure}

The same procedure was applied to all participants and each participant was tested individually in a quiet room with a computer. The testing session began with oral instructions regarding the recall test and the participant was given written instructions for the "Remember/Know/ Guess" judgements procedure that accompanied recall. They were told that they would hear an audio recording of 12 lists of words and that they would be tested for each list after they learned all the lists. The lists were presented in random order for each participant and memory was tested after each list. The registered words were spoken at a rate of one word every $1.5 \mathrm{~s}$ and the durations of the recorded lists ranged from 34 to $37 \mathrm{~s}$. To avoid retrieval of items from short-term memory, a 30-s distractor task (a backward digit-span task) was inserted between the learning and free recall phases. For each recall phase, participants were instructed to write down as many words as possible from the list which they had just heard, in no particular order. The experimenter strongly encouraged the participants to avoid guessing. They were given $90 \mathrm{~s}$ to complete each recall phase. During this recall phase, participants indicated for each word one of three judgement types ("Remember/ Know/Guess"). After having recalled all the lists, participants were instructed to say if, during the learning phase or during the recall phase, a word came to their mind, but that they did not write it down during the recall task, because they thought that the recording voice had not produced it (the post-recall test). Then, participants were asked to complete a French-language adaptation of the MHVS to assure that both groups were equivalent concerning lexical network. Finally, they were fully debriefed about the study.

\section{Results}

\section{Demographic data}

The descriptive data are presented in Table 1. For all the following analyses, the alpha level was set at 0.05 . As can be seen in Table 1, both NDErs and matched volunteers groups matched for age $(t(38)=1.004, p=0.322)$, gender $\left(\chi^{2}(1)=0.00, p=1\right)$, years of education $(t(38)=-1.433$,
Table 1 Participants' descriptive and demographic data $(N=40)$

\begin{tabular}{llll}
\hline & NDErs & Volunteers & $p$ \\
$N=20$ & $N=20$ & \\
\hline Gender-female & $9(45 \%)$ & $9(45 \%)$ & 1 \\
Age & $60 \pm 6$ & $58 \pm 4$ & 0.322 \\
(Mean in years \pm SEM, range) & $46-69$ & $47-70$ & \\
Education level & $14 \pm 2$ & $15 \pm 2$ & 0.160 \\
(Mean in years \pm SEM, range) & $9-18$ & $2-19$ & \\
Time since NDE or accident & $29 \pm 14$ & $21 \pm 12$ & 0.111 \\
(Mean in years \pm SEM, range) & $1-61$ & $1-43$ & \\
Mill Hill & $26 \pm 4$ & $27 \pm 2$ & 0.204 \\
(Mean score out of 44 \pm SEM, range) & $15-32$ & $22-33$ & \\
\hline
\end{tabular}

SEM standard error of the mean

$p=0.160)$, time since event $(t(38)=1.631, p=0.111)$, and their mean score on the Mill Hill Vocabulary Scale $(t(38)=-1.293, p=0.204)$.

\section{Free recall}

The mean proportions of recalled studied items, critical lures, and non-critical intrusions (i.e., intrusions other than critical lures) were created by averaging the number of recalled words per category across the 12 lists.

A two-way mixed ANOVA that included Group type (NDErs vs. volunteers) and Item type (studied, critical lures, and intrusions) with repeated measures on the last factor was carried out on the mean proportions of recalled items across the lists (Table 2). The main effect of Group type $\left[F(1,38)=1.30, p=0.261, \eta^{2}=0.03\right]$ was not significant, showing that both NDErs and matched volunteers recalled similar rates of items across all item types. The analysis revealed a significant main effect of Item type $\left[F(2,76)=150.21, p=0.0000001, \eta^{2}=0.80\right]$. Justified by our predictions, false recall results were followed up with pairwise planned comparisons (see Cann, McRae, \& Katz, 2011; Dehon, 2006). Pairwise planned comparisons revealed that participants recalled significantly more studied items $(M=0.45, \mathrm{SD}=0.10)$ and critical lures $(M=0.45, \mathrm{SD}=0.20)$ than intrusions $(M=0.04, \mathrm{SD}=0.03)$ $\left[F(1,38)=583.81, p=0.00004, \eta^{2}=0.99\right]$, while proportions of studied items and critical lures were equivalent $\left[F(1,38)=0.004, p=0.947, \eta^{2}=0.13\right]$. This comparison between recalled word responses to studied, critical lures, and intrusions revealed a "false memory effect" (Roediger \& McDermott, 1995), meaning that the DRM paradigm reliably created false memories in our participants (Fig. 1). Finally, the Group type $\times$ Item type interaction was not significant $\left[F(2,76)=2.465, p=.092, \eta^{2}=0.06\right]$. Justified by our predictions, pairwise planned comparisons were conducted and revealed that NDErs recalled similar mean proportions of studied items than volunteers $[F(1,38)=0.124$, 


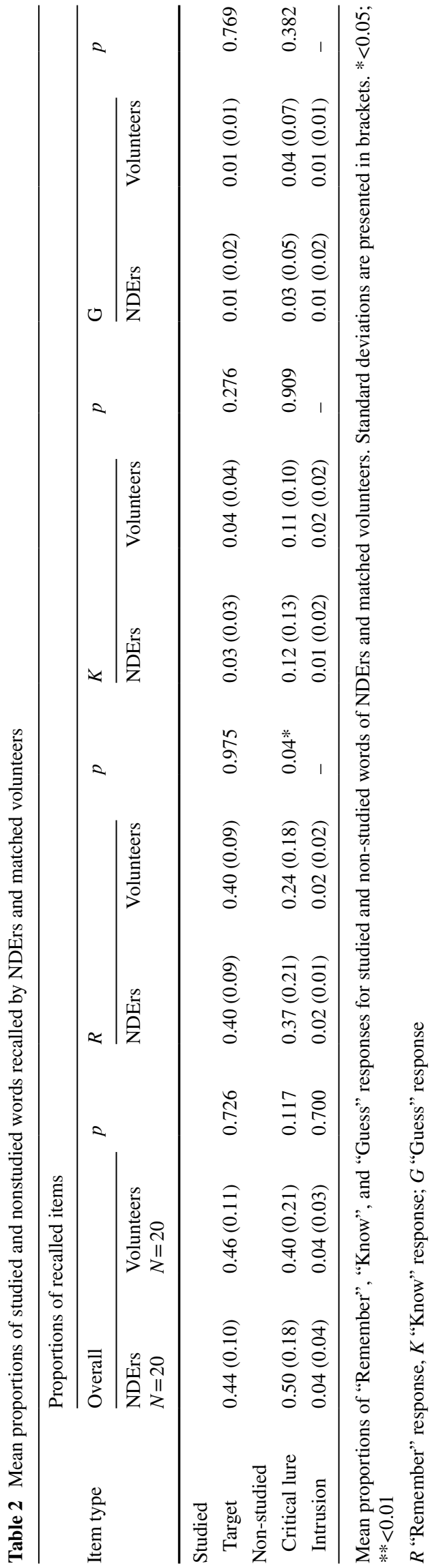

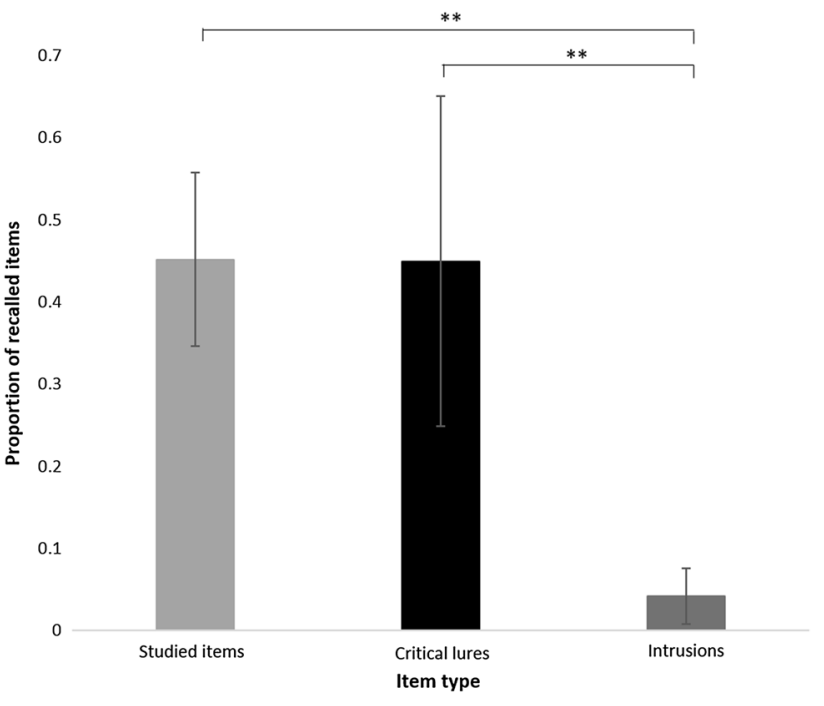

Fig. 1 Mean proportions of studied items, critical lures, and intrusions recalled at free recall test in all participants. Error bars $=$ standard deviation. $*<0.05 ; * *<0.01$

$\left.p=0.726, \eta^{2}=0.82\right]$ (see Table 2). Numerically, NDErs falsely recalled critical lures more than volunteers in the free recall phase, but this did not reached significance $\left[F(1,38)=2.569, p=0.117, \eta^{2}=0.99\right]$. The proportions of intrusions were not significantly different between both groups $\left[F(1,38)=0.150, p=0.700, \eta^{2}=0.85\right]$. Because the mean proportions of non-critical intrusions recalled by each participant were very low $(\leq 0.04)$ (Table 2$)$, they were not submitted to subsequent statistical analyses.

\section{"Remember", "Know”, and "Guess” responses}

The mean proportions of "Remember/Know/Guess" judgements assigned to recalled items were created by averaging the number of recalled words per category and per judgement across the 12 lists and are presented in Table 2.

A similar two-way mixed ANOVA that included Group type (NDErs vs. volunteers) and Item type (studied vs. critical lure) with repeated measures on the last factor was carried out on the mean proportions of "Remember" judgements assigned to studied items and critical lures (Table 2). The main effect of Group type was not significant $\left[F(1,38)=3.709, \quad p=0.061, \quad \eta^{2}=0.09\right]$, indicating that NDErs and volunteers made similar proportions of "Remember" responses across all item types. Results indicated a significant main effect of Item type $[F(1,38)=7.967$, $\left.p=0.007, \eta^{2}=0.17\right]$, showing that "Remember" responses were more likely to be attributed to studied items $(M=0.40$, $\mathrm{SD}=0.08)$ than critical lures $(M=0.30, \mathrm{SD}=0.20)$. The Group type $\times$ Item type interaction was not significant $\left[F(1,38)=3.638, p=0.064, \eta^{2}=0.09\right]$. Interestingly, pairwise planned comparisons revealed that "Remember" 


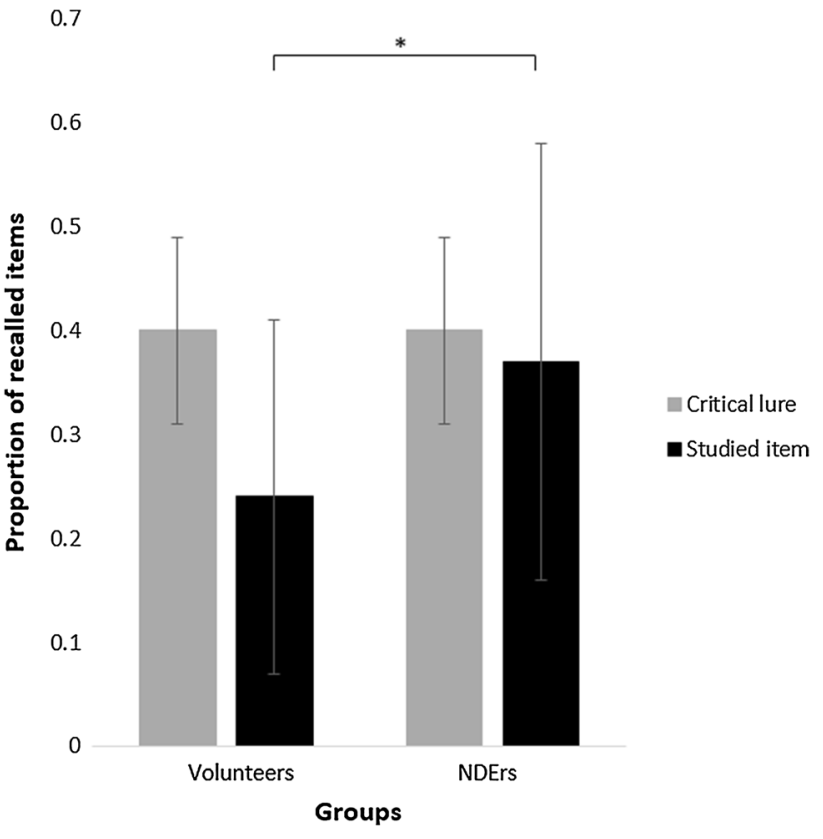

Fig. 2 Mean proportions of critical lures and studied items recalled with "Remember" responses at free recall test in each group, NDErs and matched volunteers. Error bars $=$ standard deviation. $*<0.05$; $* *<0.01$

Table 3 Mean proportions of critical lures produced by NDErs and matched volunteers in the free recall test and in the post-recall test

\begin{tabular}{llll}
\hline Tests & $\begin{array}{l}\text { NDErs } \\
N=20\end{array}$ & $\begin{array}{l}\text { Volunteers } \\
N=20\end{array}$ & $p$ \\
\hline $\begin{array}{l}\text { Free recall test } \\
\text { Critical lure }\end{array}$ & $0.50(0.18)$ & $0.40(0.21)$ & 0.117 \\
$\begin{array}{c}\text { Post-recall test } \\
\text { Critical lure }\end{array}$ & $0.02(0.07)$ & $0.12(0.20)$ & $0.04 *$ \\
$\begin{array}{l}\text { Summed proportions } \\
\text { Critical lure }\end{array}$ & $0.52(0.19)$ & $0.52(0.23)$ & 0.998 \\
\hline
\end{tabular}

Summed proportions of critical lures recalled at free recall test and critical lures produced during the post-recall test in NDErs and matched volunteers. Standard deviations are presented in brackets. $*<0.05 ; * *<0.01$

proportions assigned to studied items were similar in both groups $\left[F(1,38)=0.001, p=.975, \eta^{2}=0.04\right]$ (see Table 2). By contrast, NDErs obtained higher proportions regarding to "Remember" responses attributed to critical items than those of volunteers $\left[F(1,38)=4.377, p=0.04, \eta^{2}=0.99\right]$ (Fig. 2). In the volunteers group, pairwise planned comparisons revealed that they were more likely to assign "Remember" responses to studied items than critical items $\left[F(1,38)=11.187, p=0.001, \eta^{2}=0.18\right]$. No other significant differences were found with planned comparisons.

Next, the same analysis made on "Know" judgements assigned to recalled items (Table 2) revealed a significant main effect of Item type $[F(1,38)=25.494$, $\left.p=0.00001, \eta^{2}=0.40\right]$, indicating that proportions of "Know" responses attributed to studied items were significantly smaller than those attributed to critical lures $(M=0.03, \mathrm{SD}=0.03$ and $M=0.11, \mathrm{SD}=0.11$, respectively). The main effect of Group type and the interaction were not significant $\left[F(1,38)=0.036, p=0.850, \eta^{2}=0.01\right]$ and $\left[F(1,38)=0.283, p=0.597, \eta^{2}=0.01\right]$, respectively. Both groups obtained similar proportions of "Know" judgements for studied items and critical lures, respectively $\left[F(1,38)=1.223, p=0.276, \eta^{2}=0.98\right]$ and $[F(1,38)=0.013$, $\left.p=0.909, \eta^{2}=0.33\right]$. In both groups, pairwise planned comparisons revealed that they were more likely to assign "Know" responses to critical lures than studied items $\left[F(1,38)=15.579, p=0.0003, \eta^{2}=0.22\right]$ for NDErs group and $\left[F(1,38)=10.199, p=0.002, \eta^{2}=0.20\right]$ for volunteers group (see Table 2). No other significant differences were found with planned comparisons.

Finally, the same analysis was conducted on the proportions of "Guess" judgements assigned to recalled items (Table 2). Results revealed a significant effect of Item type $\left[F(1,38)=7.653, p=0.008, \eta^{2}=0.17\right]$, demonstrating that proportions of "Guess" responses attributed to studied items were significantly smaller than those attributed to critical lures $(M=0.01, \mathrm{SD}=0.01$ and $M=0.04, \mathrm{SD}=0.06$, respectively). The main effect of Group type and the Group type $\mathrm{x}$ Item type interaction $[F(1,38)=0.526, p=0.473$, $\left.\eta^{2}=0.01\right]$ and $\left[F(1,38)=1.058, \quad p=0.310, \quad \eta^{2}=0.03\right]$, respectively, was not significant. Planned comparisons revealed that in the volunteers group, "Guess" judgements assigned to critical lures were significantly higher than those assigned to studied items $[F(1,38)=7.202, p=0.01$, $\left.\eta^{2}=0.99\right]$ (see Table 2). By contrast, those two proportions were similar in NDErs $[F(1,38)=1.509, p=0.227$, $\left.\eta^{2}=0.98\right]$. No other significant differences were found with planned comparisons.

\section{Production of the critical lure during the post-recall test}

The proportions of critical lures produced during the postrecall test were computed for both NDErs and volunteers groups across all lists (Table 3). As expected, the analysis showed that volunteers recalled a higher proportion of critical lures during this phase $(t(38)=-2.107, p=0.04)$ than NDErs (Fig. 3).

Additional analyses were performed to observe activation and monitoring performance rates in both groups. The summed proportions of critical lures recalled at free recall test and critical lures produced during the post-recall test were calculated in both groups for studied items and critical lures (see Brédart, 2000; Dehon, 2006; Dehon \& Brédart, 2004 for more information) to obtain an estimate 


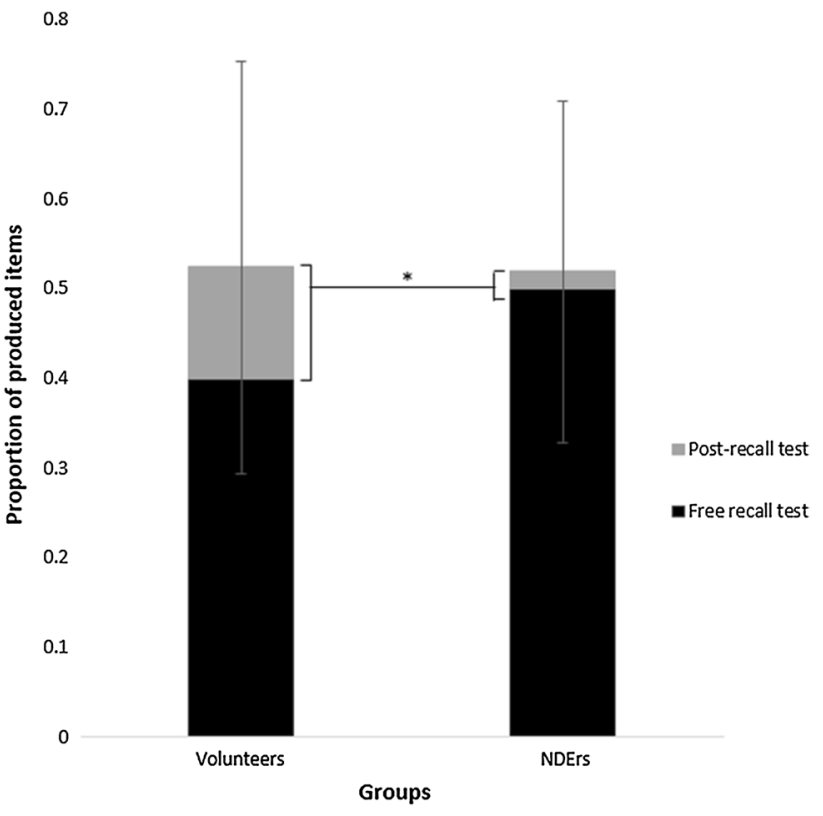

Fig. 3 Mean proportions of critical lures recalled at free recall test and critical lures produced during the post-recall test in NDErs and matched volunteers. Error bars $=$ standard deviation. $*<0.05$; $* *<0.01$

of activation rate of critical lures (see Table 3 ). The analysis showed that mean proportions of activated critical lures were similar $(t(38)=0.002, p=.998)$ in both groups (see Table 3). This indicates that critical lures were equally often activated during the experiment in NDErs and volunteers, but NDErs were less likely to recall them during the post-recall test.

\section{Discussion}

The objective of the present study was to investigate false memory production and illusory recollection using the DRM false memory paradigm in people who have experienced a NDE. More specifically, this study examined NDErs' performance in the DRM false memory paradigm and compared their estimates of monitoring and activation of critical lures, as compared to a matched cohort without NDEs. We also measured illusory recollections in both groups in this procedure using the "Remember/Know/ Guess" procedure (Tulving, 1985).

Several findings emerge from this pioneer study. First, the DRM task reliably created false memories in our participants - the so-called "false memory effect" (i.e., the rates of false recall of critical lures were far higher than that of other non-critical intrusions; Roediger \& McDermott, 1995). Overall, the rates of recall of non-critical intrusions were very low (an average of 0.04) in all our participants, indicating that recall rates for critical lures were not due to guessing (see also rates of "Guess" judgements). Therefore, our findings replicate the previous research that has used the DRM paradigm to induce substantial rates of compelling false memories (e.g., Dehon, 2012).

Second, we obtained equivalent proportions of correct and false recall performance in both groups. Yet, if one considers the subjective experience (as measured with "Remember/Know/Guess" judgements) associated with recalled items, we observed that judgements assigned to recalled studied items were equivalent in both groups, suggesting that both groups were also equally confident that those items had occurred. By contrast, the subjective experience associated with false recall reveals a different pattern. That is, NDErs more frequently attributed to false recall a "Remember" response that was associated to a conscious recollection state to false recall, whereas there was no statistically significant difference for the rates of false recall between both groups. This suggests that while NDErs did not produce significantly more false memories, those that were produced were more often associated with illusory recollection. The false memories accompanied with illusory recollection are compelling, since participants are very confident that the critical lure has occurred, and are able to give details regarding its presentation, although it was never presented. Following the "conscious activation" account (e.g., Roediger \& McDermott, 1995), illusory recollection appears, because people may generate the critical lures during the learning phase and later remember the characteristics of these generations as justifications that the critical lures were presented in the previous lists (Lampinen, Ryals, \& Smith, 2008). Alternatively, illusory recollection may occur due to the integration of misleading retrieval cues (e.g., a voice that did not correspond to the voice that originally produced the list words; see the "imagination account"; Dobson, 2007) into the recollective experience (e.g., Whittlesea, 2002; Whittlesea \& Williams, 1998, 2000). Similarly, illusory recollection might occur, because the feeling of familiarity leads to a search for details in memory that corroborate the distractors (see the "familiarity plus corroboration account"; e.g., Lampinen et al., 2008). In addition, we also observed that volunteers more frequently attributed a "Guess" response that was associated to an absence of subjective experience to false recall than correct recall-which was not the case in NDErs. This is consistent with the above findings, suggesting qualitatively different forms of memory experiences associated with false and correct recall in both groups.

Overall, the heightened emergence of illusory recollection in NDErs might possibly explain why NDErs perceived their NDE as a "more real than real" type of memory (Thonnard et al., 2013). Since NDEs are experienced during episodes of altered consciousness (Greyson \& 
Stevenson, 1980; Ring, 1980) and that the perceptive features can be ambiguous at this moment, processes involved in memory encoding can be increasingly active and influence the lived subjective experience. Indeed, to preserve a coherent interpretation of the lived experience during this peculiar state of altered consciousness, NDErs' expectations, beliefs, or knowledge can influence the encoded event and the accompanying subjective experience. Finally, NDErs' cognitive processing style might then lead to a highly subjective and very detailed episodic representation of the event.

Third, we used a variant of the DRM task to separately estimate activation and monitoring processes (cf. Brédart, 2000). This allowed us to determine, in both groups, whether false memory production is caused by a higher activation process or by a reduced monitoring process. We found that NDErs were less likely to produce critical lures during the post-recall test, while both groups were equally as likely to recall non-presented critical lures during the initial recall. In addition, the sum of produced critical lures in the recall test and in the post-recall test indicated that critical lures were activated during the experiment equally often in NDErs and volunteers groups. This suggests that NDErs were as prone as their matched volunteers to think of the critical lures and that the monitoring explanation is a likely account for the non-occurrence of a false memory in volunteers but less so in NDErs. The fact that volunteers reported critical lures during the post-recall test for presented lists indicates more efficient source monitoring abilities than those of NDErs. According to the activationmonitoring account (e.g., McDermott \& Watson, 2001; Roediger et al., 2001), false memories occur, because the critical lure is activated during the presentation of the associated words in the list or during the subsequent recall of those. This activation mechanism seems to be equally effective in both groups, importantly, not more frequent in NDErs. In the case of our participants, NDErs seem to more often mistakenly attribute the memory of the word to the list presentation rather than their own thoughts and this may reflect a bias in the monitoring of internal events that is influenced by top-down processes (e.g., the individual's beliefs and expectations). More broadly, the present findings raise the challenging question of whether (and how) non-NDErs also experience similar episodes as NDEs but directly (or later) categorize them as internally generated events. This would be consistent with the less efficient source monitoring processes observed in NDErs here, however, further studies are needed to explore this hypothesis.

Several speculative hypotheses may explain the heightened emergence of illusory recollection and reduction in source monitoring in NDErs. We observed that NDErs are as likely to encode and reconstruct information (i.e., identical rate of false memories) than non-NDErs; however, their cognitive processing style then leads them to recall a greater detailed subjective feeling of remembering information that was not actually experienced. One hypothesis could be that NDErs, as high dissociators (Greyson, 2000b), are characterized by a distinct cognitive processing style involving enhanced attention and working memory abilities (de Ruiter et al., 2006). The previous studies have shown that non-pathological individuals with high-dissociative abilities present an enhanced elaborative encoding (Elzinga, Phaf, Ardon, \& Van Dyck, 2003; see; de Ruiter et al., 2006 for a review). This distinct ability could, in turn, lead those individuals to make illusory recollection of such a kind more likely. Then, compelling illusory recollection may make it even more difficult to discriminate information that they thought of from those that had actually been experienced (source monitoring abilities). However, further work is needed to precisely investigate NDErs' attention and working memory capacities and encoding process of experiences.

In addition to this interpretation, another hypothesis could be advanced to explain our results. It can be envisioned that specific experience such as NDEs results in a change in processing memory information leading to higher levels of illusory recollection creation. Susceptibility to false memories and its associated rich phenomenology can be influenced by different factors. Notably, the false memory literature has shown that positive moods and emotions are associated with higher susceptibility to misinformation than are negative moods (Forgas, Laham, \& Vargas, 2005; in the case of DRM paradigm: Storbeck \& Clore, 2005, 2011). Positive moods are associated with more general schematic processing, resulting in increasing the semantic activation and thus producing false memories in the DRM procedure (Roediger et al., 2001). As NDErs tend to have more positive views of future experiences after having lived their NDE and persistent positive aftereffects (Atwater, 2001; Ring, 1980), their encoding process may be modified after experiencing a NDE. This might then explain the observed pattern of results of our study, by admitting that NDErs likely retain more general information, rather than specific information (Schacter \& Slotnick, 2004).

Some authors have suggested that NDE memories can be comparable to false memories, based on their beliefs and rich fantasies (e.g., Braithwaite, 2008; French, 2001). Our study cannot conclude that the subjective experience associated with NDE is illusory recollection, but the present results do suggest that NDErs are more likely than non-NDErs to illusory recollect details associated with the supposed presentation of non-presented items. NDEs have been associated with a very rich phenomenology; however, future studies are needed to know if perceived and reported phenomenological characteristics of NDE are associated with an actual event-i.e., appropriate stimulus in reality. 
To date, we do not know clear characteristics that collectively specify the conditions under which a NDE appears and our results suggest that this phenomenon, or at least its associated rich phenomenology, occurring spontaneously in the life of certain individuals might be explained, at least partly, by psychological mechanisms. One interesting issue is whether this cognitive processing style which leads to more illusory recollection is particularly active for the specific case of NDE memories, and if it is, knowing when it occurs (i.e., during the experience or later). Moreover, this seems to be sustained over time as reports of NDEs appear not to be modified over time (even 20 years after the original account; Greyson, 2007). Finally, another interesting issue is the extent to which NDEs memories retain episodic (e.g., visuospatial details, emotions, and thoughts from the experience) versus semantic (e.g., general facts) memory details. Considering our results, we may formulate the hypothesis that NDEs memories would contain more episodic details, compared to other memories. It would also be interesting to investigate whether, in general, episodic details are preferably encoded in NDErs' memory.

Nevertheless, there are some limitations of this study that deserve mention. First, the extent to which these findings from such laboratory situations are generalizable. The ecological validity of false memories created by the DRM paradigm has been discussed (Pezdek, 2007; Wade et al., 2007), because memories of word lists are, by design, less complex than autobiographical memories. Further studies are needed to examine the cognitive processing style of NDErs population in the context of more complex false and true autobiographical memories.

Second, we must take into account that our participants were a little older than typical populations in DRM studies. Indeed, partly because NDErs decided to share their experience belatedly, they are in the range of 40-60 years old. The susceptibility to DRM false memories has been shown to increase with age (e.g., Dehon \& Bredart, 2004; Gallo \& Roediger, 2003; see: Schacter, Koutstaal, \& Norman, 1997 for a review). Investigations have generally demonstrated some evidence for impaired source memory in older adults under conditions in which recollection performance of both young and old population has been equated experimentally (Schacter, Osowiecki, Kaszniak, Kihlstrom, \& Valdiserri, 1994). However, on one hand, compared to research literature on DRM false recall, our rates of true and false recall seem to be consistent with the previous studies (e.g., Dehon \& Bredart, 2004) and this limit was taken into account when selecting a matched volunteers group. On the other hand, volunteers were matched for age, even though one cannot rule out the possibility that this may have masked differences between our NDErs and volunteers groups.

Finally, another related question concerns the retrospective assessment of their cognitive functioning. The retrospective design of this study does not allow us to say whether NDEs occur more frequently in people with increased illusory recollection or whether such experiences induce increased illusory recollection in people who were previously not prone to this. Although we found an increase of illusory recollection in NDErs, the question of cause and effect can be answered only by a prospective study in which illusory recollection is assessed in individuals before and after their NDEs.

Although further work is required to examine cognitive performance in NDErs, this study opens a field of investigation and brings out issues concerning the creation of illusory recollection by NDErs. In a longer term perspective, a better understanding of NDErs' cognitive functioning will lead to better evaluation of the characteristics of their memories and thus, their NDE memories. The challenge will be to understand the skills that might underlie NDErs' source monitoring ability and whether illusory recollection that originates from conscious generation of critical lures is associated to individual differences in information processing.

\section{Conclusion}

In conclusion, the present study showed that NDErs and matched volunteers without a NDE were equally likely to produce false memories, but that NDErs were more likely to associate them with compelling illusory recollection (i.e., a detailed subjective feeling of remembering items that actually were not presented). Moreover, NDErs seem to have more difficulty in later identifying the source of information that was activated as a consequence of intact semantic activation processes in the DRM paradigm. Since the research data on the cognitive processing style in NDErs are still quite sparse, this study constitutes a first approach toward understanding their memory formation and, more generally, their cognitive processing style. Further studies are needed to examine the contents and the origin of this illusory recollection in NDErs. Clarification of mechanisms underlying the recall and encoding of the NDEs should allow us to complete the scientific understanding of the NDE phenomenon and, in general, enhance our understanding of memory.

Acknowledgements The authors would like to thank our subjects for contributing their time to participate in this study. The authors thank Dr. Frank Larøi and Dr. Armand Mensen for reviewing the manuscript and providing their insightful comments.

\section{Compliance with ethical standards}

Funding This study was funded by the Belgian National Funds for Scientific Research (FNRS), the French Speaking Community Con- 
certed Research Action (ARC-06/11-340), NSERC discovery grant, IAP research network P7/06 of the Belgian Government (Belgian Sci- ence Policy), the European Commission, the BIAL Foundation (grant number: 503323 055), the James McDonnell Foun- dation, Mind Science Foundation, and the European space agency (ESA).

Conflict of interest The authors declare that they have no conflict of interest.

Ethical approval All procedures performed in studies involving human participants were in accordance with the ethical standards of the institutional and/or national research committee and with the 1964 Helsinki declaration and its later amendments or comparable ethical standards.

Informed consent Informed consent was obtained from all individ- ual participants included in the study.

\section{References}

Agrillo, C. (2011). Near-death experience: out-of-body and out-ofbrain? Review of General Psychology, 15(1), 1-10.

Atwater, P. M. H. (2001). Coming back to life: Examining the after- effects of the near-death experience. New York: Ballantine Book.

Beauregard, M., Courtemanche, J., \& Paquette, V. (2009). Brain activity in near-death experiencers during a meditative state. Resuscitation, 80(9), 1006-1010.

Belanti, J., Perera, M., \& Jagadheesan, K. (2008). Phenomenology of near-death experiences: A cross-cultural perspective. Transcul- tural Psychiatry, 45(1), 121-133.

Bernstein, E. M., \& Putnam, F. W. (1986). Development, reliability, and validity of a dissociation scale. The Journal of Nervous and Mental Disease, 174, 727-735.

Blackmore, S. (1993). Dying to live: Near-death experiences. New York: Prometheus Books.

Blanke, O., \& Dieguez, S. (2009). Leaving body and life behind: Out- of-body and near-death experience. In S. Laureys \& G. Tononi (Eds.), The neurology of consciousness (pp. 303325). London: Academic Publishers.

Brainerd, C. J., Wright, R., Reyna, V. F., \& Mojardin, A. H. (2001). Conjoint recognition and phantom recollection. Journal of Experimental Psychology: Learning, Memory, and Cognition, 27(2), 307-327.

Braithwaite, J. J. (2008). Towards a cognitive neuroscience of the dying brain. Skeptic, 21, 8-16.

Brédart, S. (2000). When false memories do not occur: Not thinking of the lure or remembering that it was not heard? Memory (Hove, England), 8, 123-128.

Cabeza, R., Rao, S. M., Wagner, A. D., Mayer, A. R., \& Schacter, D. L. (2001). Can medial temporal lobe regions distinguish true from false $\dagger^{-}$? An event-related functional MRI study of veridical and illusory recognition memory. Proceedings of the National Academy of Sciences, 98(8), 4805-4810.

Cann, D., McRae, K., \& Katz, A. (2011). False recall in the Deese- Roediger-McDermott paradigm: The roles of gist and associa- tive strength. The Quarterly Journal of Experimental Psychol-ogy, 64(8), 1515-1542.

Charland-Verville, V., Jourdan, J. P., Thonnard, M., Ledoux, D., Don- neau, A. F., Quertemont, E., \& Laureys, S. (2014). Near-death experiences in non-life-threatening events and coma of different etiologies. Frontiers in Human Neuroscience, 8, 203.
Clancy, S. A., McNally, R. J., Schacter, D. L., Lenzenweger, M. F., \& Pitman, R. K. (2002). Memory distortion in people reporting abduction by aliens. Journal of Abnormal Psychology, $111,455-461$.

de Ruiter, M. B., Elzinga, B. M., Phaf, R. H., \& de Ruiter, M. B. (2006). Dissociation ${ }^{-}$: Cognitive Capacity or Dysfunction $\dagger^{-}$? Journal of Trauma and Dissociation, 7, 115134.

Deese, J. (1959). On the prediction of occurrence of particular verbal intrusions in immediate recall. Journal of Experimental Psychology, 58(1), 17-22.

Dehon, H. (2006). Variations in processing resources and resistance to false memories in younger and older adults. Memory (Hove, England), 14, 692-711.

Dehon, H. (2012). Illusory recollection: the compelling subjective remembrance of things that never happened. Insights from the DRM paradigm. Psychologica Belgica, 52, 121-149.

Dehon, H., Bastin, C., \& Larøi, F. (2008). The influence of delusional ideation and dissociative experiences on the resistance to false memories in normal healthy subjects. Personality and Individual Differences, 45, 62-67.

Dehon, H., \& Bredart, S. (2004). False memories: Young and older adults think of semantic associates at the same rate, but young adults are more successful at source monitoring. Psychology and Aging, 19, 191-197.

Dehon, H., Larøi, F., \& Van der Linden, M. (2011). The influence of encoding style on the production of false memories in the DRM paradigm: new insights on individual differences in false memory susceptibility. Personality and Individual Differences, 50, 583-587.

Dell'Olio, A. J. (2010). Do near-death experiences provide a rational basis for belief in life after death? Sophia, 49, 113128.

Deltour, J.J. (1993). Échelle de Vocabulaire Mill Hill de J. C. Raven: Adaptation Française et normes comparées du Mill Hill et du Standard Progressive Matrices (PM38). Braine-leChâteau: Edi- tions L'Application des Techniques Modernes SPRL.

Dobson, C. S. (2007). Retrieval-based illusory recollections: Why study-test contextual changes impair source memory. Memory and Cognition, 35, 1211-1221.

Ellwood, G. F. (2000). Religious experience, religious worldviews, and near-death studies. Journal of Near Death Studies, 19, 5-21.

Elzinga, B. M., Phaf, R. H., Ardon, A. M., \& Van Dyck, R. (2003). Directed forgetting between, but not within, dissociative personality states. Journal of Abnormal Psychology, 112, 237-242.

Facco, E., \& Agrillo, C. (2012). Near-death-like experiences without life-threatening conditions or brain disorders: A hypothesis from a case report. Frontiers in Psychology, 3, 16.

Farina, B., \& Liotti, G. (2013). Does a dissociative psychopathologi- cal dimension exist ? A review on dissociative processes and symptoms in developmental trauma spectrum disorders. Clinical Neuropsychiatry, 10(1), $11-18$.

Forgas, J. P., Laham, S. M., \& Vargas, P. T. (2005). Mood effects on eyewitness memory: Affective influences on susceptibility to misinformation. Journal of Experimental Social Psychology, 41, 574-588.

French, C. C. (2001). Dying to know the truth: Visions of a dying brain, or false memories? Lancet, 358, 2010-2011.

Gallo, D. (2006). Associative illusions of memory: associative illusions of memory: False memory research in drm and related tasks. New York: Psychology Press.

Gallo, D. (2010). False memories and fantastic beliefs: 15 years of the DRM illusion. Memory and Cognition, 38(7), 833-848.

Gallo, D., McDermott, K.B., Percer, J.M., \& Roediger, H.L. (2001). Modality effects in false recall and false recognition. Journal of Experimental Psychology: Learning, Memory, and Cognition, $27,339-353$ 
certed Research Action (ARC-06/11-340), NSERC discovery grant, IAP research network P7/06 of the Belgian Government (Belgian Science Policy), the European Commission, the James McDonnell Foundation, Mind Science Foundation, and the European space agency (ESA)

Conflict of interest The authors declare that they have no conflict of interest.

Ethical approval All procedures performed in studies involving human participants were in accordance with the ethical standards of the institutional and/or national research committee and with the 1964 Helsinki declaration and its later amendments or comparable ethical standards.

Informed consent Informed consent was obtained from all individual participants included in the study.

\section{References}

Agrillo, C. (2011). Near-death experience: out-of-body and out-ofbrain? Review of General Psychology, 15(1), 1-10.

Atwater, P. M. H. (2001). Coming back to life: Examining the aftereffects of the near-death experience. New York: Ballantine Book.

Beauregard, M., Courtemanche, J., \& Paquette, V. (2009). Brain activity in near-death experiencers during a meditative state. Resuscitation, 80(9), 1006-1010.

Belanti, J., Perera, M., \& Jagadheesan, K. (2008). Phenomenology of near-death experiences: A cross-cultural perspective. Transcultural Psychiatry, 45(1), 121-133.

Bernstein, E. M., \& Putnam, F. W. (1986). Development, reliability, and validity of a dissociation scale. The Journal of Nervous and Mental Disease, 174, 727-735.

Blackmore, S. (1993). Dying to live: Near-death experiences. New York: Prometheus Books.

Blanke, O., \& Dieguez, S. (2009). Leaving body and life behind: Outof-body and near-death experience. In S. Laureys \& G. Tononi (Eds.), The neurology of consciousness (pp. 303-325). London: Academic Publishers

Brainerd, C. J., Wright, R., Reyna, V. F., \& Mojardin, A. H. (2001). Conjoint recognition and phantom recollection. Journal of Experimental Psychology: Learning, Memory, and Cognition, 27(2), 307-327.

Braithwaite, J. J. (2008). Towards a cognitive neuroscience of the dying brain. Skeptic, 21, 8-16.

Brédart, S. (2000). When false memories do not occur: Not thinking of the lure or remembering that it was not heard? Memory (Hove, England), 8, 123-128.

Cabeza, R., Rao, S. M., Wagner, A. D., Mayer, A. R., \& Schacter, D. L. (2001). Can medial temporal lobe regions distinguish true from false $\dagger^{-}$? An event-related functional MRI study of veridical and illusory recognition memory. Proceedings of the National Academy of Sciences, 98(8), 4805-4810.

Cann, D., McRae, K., \& Katz, A. (2011). False recall in the DeeseRoediger-McDermott paradigm: The roles of gist and associative strength. The Quarterly Journal of Experimental Psychology, 64(8), 1515-1542.

Charland-Verville, V., Jourdan, J. P., Thonnard, M., Ledoux, D., Donneau, A. F., Quertemont, E., \& Laureys, S. (2014). Near-death experiences in non-life-threatening events and coma of different etiologies. Frontiers in Human Neuroscience, 8, 203.
Clancy, S. A., McNally, R. J., Schacter, D. L., Lenzenweger, M. F., \& Pitman, R. K. (2002). Memory distortion in people reporting abduction by aliens. Journal of Abnormal Psychology, $111,455-461$.

de Ruiter, M. B., Elzinga, B. M., Phaf, R. H., \& de Ruiter, M. B. (2006). Dissociation $\dagger^{-}$: Cognitive Capacity or Dysfunction $\dagger^{-}$? Journal of Trauma and Dissociation, 7, 115-134.

Deese, J. (1959). On the prediction of occurrence of particular verbal intrusions in immediate recall. Journal of Experimental Psychology, 58(1), 17-22.

Dehon, H. (2006). Variations in processing resources and resistance to false memories in younger and older adults. Memory (Hove, England), 14, 692-711.

Dehon, H. (2012). Illusory recollection: the compelling subjective remembrance of things that never happened. Insights from the DRM paradigm. Psychologica Belgica, 52, 121-149.

Dehon, H., Bastin, C., \& Larøi, F. (2008). The influence of delusional ideation and dissociative experiences on the resistance to false memories in normal healthy subjects. Personality and Individual Differences, 45, 62-67.

Dehon, H., \& Bredart, S. (2004). False memories: Young and older adults think of semantic associates at the same rate, but young adults are more successful at source monitoring. Psychology and Aging, 19, 191-197.

Dehon, H., Larøi, F., \& Van der Linden, M. (2011). The influence of encoding style on the production of false memories in the DRM paradigm: new insights on individual differences in false memory susceptibility. Personality and Individual Differences, 50, 583-587.

Dell'Olio, A. J. (2010). Do near-death experiences provide a rational basis for belief in life after death? Sophia, 49, $113-128$.

Deltour, J.J. (1993). Échelle de Vocabulaire Mill Hill de J. C. Raven: Adaptation Française et normes comparées du Mill Hill et du Standard Progressive Matrices (PM38). Braine-le-Château: Editions L'Application des Techniques Modernes SPRL.

Dobson, C. S. (2007). Retrieval-based illusory recollections: Why study-test contextual changes impair source memory. Memory and Cognition, 35, 1211-1221.

Ellwood, G. F. (2000). Religious experience, religious worldviews, and near-death studies. Journal of Near Death Studies, 19, 5-21.

Elzinga, B. M., Phaf, R. H., Ardon, A. M., \& Van Dyck, R. (2003). Directed forgetting between, but not within, dissociative personality states. Journal of Abnormal Psychology, 112, 237-242.

Facco, E., \& Agrillo, C. (2012). Near-death-like experiences without life-threatening conditions or brain disorders: A hypothesis from a case report. Frontiers in Psychology, 3, 1-6.

Farina, B., \& Liotti, G. (2013). Does a dissociative psychopathological dimension exist? A review on dissociative processes and symptoms in developmental trauma spectrum disorders. Clinical Neuropsychiatry, 10(1), 11-18.

Forgas, J. P., Laham, S. M., \& Vargas, P. T. (2005). Mood effects on eyewitness memory: Affective influences on susceptibility to misinformation. Journal of Experimental Social Psychology, 41 , 574-588.

French, C. C. (2001). Dying to know the truth: Visions of a dying brain, or false memories? Lancet, 358, 2010-2011.

Gallo, D. (2006). Associative illusions of memory: associative illusions of memory: False memory research in drm and related tasks. New York: Psychology Press.

Gallo, D. (2010). False memories and fantastic beliefs: 15 years of the DRM illusion. Memory and Cognition, 38(7), 833-848.

Gallo, D., McDermott, K.B., Percer, J.M., \& Roediger, H.L. (2001). Modality effects in false recall and false recognition. Journal of Experimental Psychology: Learning, Memory, and Cognition, 27, 339-353. 
Wade, K., Sharman, S. J., Garry, M., Memon, A., Mazzoni, G., Merckelbach, H., \& Loftus, E. (2007). False claims about false memory research. Consciousness and Cognition, 16(1), 18-28.

Whittlesea, B.W.A. (2002). False memory and the discrepancy-attribution hypothesis: The prototype-familiarity illusion. Journal of Experimental Psychology: General, 131, 96-115.

Whittlesea, B.W.A., \& Williams, L. D. (1998). Why do strangers feel familiar, but friends don't? A discrepancy-attribution account of feelings of familiarity. Acta Psychologica, 96, 141-165.
Whittlesea, B.W.A., \& Williams, L. D. (2000). The source of feelings of familiarity: The discrepancy-attribution hypothesis. Journal of Experimental Psychology: Learning, Memory and Cognition, 26(3), 547-565.

Winograd, E., Peluso, J. P., \& Glover, T. A. (1998). Individual differences in Susceptibility to memory illusions. Applied Cognitive Psychology, 12(7), 5-27. 